\title{
Quality of life of Portuguese and Spanish adolescents. A comparative study between natives and immigrants
}

\author{
Qualidade de Vida nos adolescentes portugueses e espanhóis. \\ Um estudo comparativo entre nativos e imigrantes
}

\author{
Cristina Nunes ${ }^{1}$ \\ Ángel Hernando ${ }^{2}$ \\ Ida Lemos ${ }^{1}$ \\ Lara Ayala-Nunes ${ }^{3}$ \\ Cristina Romero Oliva ${ }^{2}$ \\ Cecilia Montilla Coronado ${ }^{2}$
}

${ }^{1}$ Centro de Investigação sobre Espaço e

Organizações, Universidade do Algarve. Campus de Gambelas 8005-139. Faro

Algarve Portugal.

csnunes@ualg.pt

${ }^{2}$ Departamento de

Psicología y Educación,

Universidad de Huelva.

Huelva Andaluzia Espanha.

${ }^{3}$ Departamento de

Psicología y Educación,

Universidad de Sevilla.

Sevilla Andaluzia Espanha.
Abstract The aim of this study was to analyse differences in quality of life (QOL) between Spanish and Portuguese immigrant and native adolescents. In total, 475 native and immigrant adolescents (52\% boys) from Algarve (Portugal) and Huelva (Spain), aged between 12 and 17 years old, were assessed with the KIDSCREEN-52. QOL dimensions were not related to most academic variables, with the exception of number of school failures, Financial Resources and Social Support from Peers. Multivariate analysis of variance (MANOVA) was used to examine statistical differences in adolescents QOL. Age differences in QOL levels were not found. Girls reported worse QOL levels on Physical Wellbeing than boys ( $F=$ $10.32, p=.001, \eta^{2}=.02$ ). Immigrant Portuguese adolescents scored higher on Mood ( $F=17.57, p=$ $.000, \eta^{2}=.11$ ), and native Portuguese adolescents scored higher on Social Acceptance ( $F=4.87, p=$ $\left..002, \eta^{2}=.033\right)$. Immigrant and native adolescents had similar levels of perceived QOL. Overall, it seems that in both countries, the living contexts for immigrant and native adolescents are fairly homogeneous.

Key-words Quality of life, Adolescence, Immigrants, Portugal, Spain
Resumo Neste estudo são analisadas as diferenças na qualidade de vida (QVD) entre adolescentes imigrantes e nativos de Espanha e Portugal. Avaliou-se a QDV percebida de 475 adolescentes nativos e imigrantes (52\% rapazes) entre os $12 e$ os 17 anos de idade do Algarve (Portugal) e Huelva (Espanha) através do questionário KIDSCREEN-52 e o perfil sociodemográfico. As dimensões da QDV não estavam associadas à maioria das variáveis acadêmicas, excetuando o número de repetições, recursos econômicos e apoio dos pares. Para analisar as diferenças da QVD entre os adolescentes foram realizadas análises de variância multivariada (MANOVA). Não se encontraram diferenças na $Q D V$ por idade. As raparigas reportaram piores niveis de $Q D V$ no bem-estar físico do que os rapazes $\left(F=10.32, p=.001, \eta^{2}=.02\right)$. Os adolescentes portugueses imigrantes mostraram niveis mais elevados no Humor ( $F=17.57, p=$ $\left..000, \eta^{2}=.11\right)$ e os nativos obtiveram pontuações mais altas na Aceitação social ( $F=4.87, p=.002$, $\left.\eta^{2}=.033\right)$. Os resultados sugerem que os adolescentes imigrantes e nativos têm niveis semelhantes de QDV percebida. Em conjunto, parece que nos dois países os contextos vitais dos adolescentes nativos e imigrantes são bastante homogêneos.

Palavras-chave Qualidade de vida, Adolescência, Imigrantes, Portugal, Espanha 


\section{Introduction}

Quality of life (QOL) can be defined as the evaluation of individuals' health based on their psychological functioning and, to a lesser degree, physical functioning ${ }^{1}$. The major strengths of this construct are its multidimensionality and the fact that it comprises a set of determinants of children's perceived $\mathrm{QOL}^{2}$. Thus, the QOL construct comprises individuals' perception of several aspects of their health, namely, emotions, autonomy, relationships with parents, school environment, social support and peers and physical wellbeing.

Data on these dimensions have been documented in several international studies with adolescent populations $\mathrm{s}^{3-5}$. Overall, these studies have indicated that QOL is influenced by socioeconomic factors - e.g., age, gender, country of origin and socioeconomic status - and by the individuals' aims, expectations and life perspectives ${ }^{6}$. Additionally, over the last three decades, the application of QOL measures to different diseases, settings, and populations has increased ${ }^{1,7}$.

The KIDSCREEN is a widely disseminated instrument that assesses QOL and was developed in the framework of the project "Screening and promotion for health-related QOL in children and adolescents - A European public health perspective". This project was conducted in several European countries, including Portugal and Spain ${ }^{8-10}$, and the KIDSCREEN is the first cross-cultural instrument developed to evaluate QOL in children and adolescents ${ }^{4,8,11}$. Several studies using the KIDSCREEN to evaluate QOL with large community samples have found significant associations between perceived QOL and psychosocial outcomes ${ }^{5,6,12,13}$.

For instance, in a study conducted with 2412 Spanish adolescents, Vázquez et al. ${ }^{13}$ indicated that higher levels of QOL were associated with better academic indicators and fewer conduct problems. Additionally, Gaspar et al. ${ }^{6}$ assessed 3,195 Portuguese children aged between 10 and 16 years and concluded that health-related QOL is influenced by sociodemographic and family factors (such as gender, age, economic status and the quality of parent-child relationships) and by adolescents' health behaviours. This empirical work with large samples of children and adolescents has strengthened the developmental-contextual perspective of human development, which focuses on the study of interactions between the individual and contextual factors ${ }^{14}$.

The interest in studying health-related issues of immigrant children has increased over the last decade in European countries, including Spain and Portugal ${ }^{15-17}$. For instance, Santervás et al. ${ }^{15}$ compared 60 Spanish immigrant and native adolescents and concluded that immigrants received a greater number of public health services and reported significantly worse health compared to natives. Neto ${ }^{16}$ analysed 310 Portuguese immigrant adolescents and found that gender, self-esteem, and living in an ethnically homogeneous neighbourhood were predictors of life satisfaction. In Neto's ${ }^{17}$ subsequent research study, which aimed to analyse whether multi-ethnic young people are at a psychological disadvantage, Portuguese native and immigrant adolescents' wellbeing and social adaptation were compared. No significant differences were found between the two samples; therefore, the author concluded that the majority of immigrants may adapt well to their new societies, despite difficulties in meeting the demands of cultural changes and living in two cultures.

As the results of these studies indicate, research on the psychosocial adaptation and developmental outcomes of immigrant adolescents has obtained mixed findings. Addressing this topic, Berry ${ }^{18}$ stated that the integration of immigrants into a new culture requires substantial negotiation, but its outcomes depend on the integration policies and strategies of the host country. As the author claimed, further research is required to improve the conceptual clarity and empirical background of this topic. The number of studies that have specifically addressed QOL or well-being in migrant adolescents remains scarce $^{19}$. In one of the studies that have addressed this issue, Hernando et al. ${ }^{20}$ compared the QOL of immigrant adolescents from Huelva (Spain) and Algarve (Portugal) and found that the Spanish adolescents reported higher physical and psychological wellbeing than the Portuguese adolescents. In another cross-cultural study of QOL and health behaviours, Lima-Serrano et al. ${ }^{21}$ observed that, overall, Spanish adolescents reported higher levels of QOL than Portuguese adolescents. Furthermore, the authors indicated that alcohol and substance abuse during adolescence was associated with lower health-related QOL and more reports of psychological problems.

The fact that children from immigrant families represent an important portion of the child population in affluent countries ${ }^{10}$ may partially explain the increased attention to health-related issues in this population. The immigration rates in Spain and Portugal have strongly increased in the last decade ${ }^{16,22-25}$, and knowledge about the QOL of immigrant adolescents may increase our 
understanding of which dimensions or aspects of their health need intervention. This is especially relevant because youth from immigrant families tend to be disadvantaged in terms of educational opportunities, and these opportunities may differ according to their countries of origin. Factors such as a low SES and low education level, low wage jobs, and social segregation and discrimination contribute to such disadvantage ${ }^{10}$. Additionally, adolescents from disadvantaged immigrant families tend to show worse educational outcomes and poorer adaptation to school and to engage more frequently in risky behaviours compared to their native counterparts ${ }^{18}$. The main aim of the present study is to analyse differences in QOL between Spanish and Portuguese immigrant and native adolescents.

\section{Methods}

\section{Participants}

The participants were 475 adolescents (47.58\% girls and 52.42\% boys), aged between 12 and 17 years old $(M=14.40, D P=1.48)$, who were residents in the regions of Algarve (Portugal) and Huelva (Spain). Of the sample, 28.42\% were Portuguese natives, $18.11 \%$ were Portuguese immigrants, $28.84 \%$ were Spanish natives, and $24.63 \%$ were Spanish immigrants. In Table 1, we present the sociodemographic characteristics of the four groups of adolescents.

\section{Instruments}

KIDSCREEN-52,26: Evaluates the perceived QOL of children and adolescents between 8 and 18 years old and it was developed simultaneously in representative samples of several European countries. The Portuguese version was validated by Gaspar and Matos ${ }^{9}$ and the Spanish version by Pantzer et al. ${ }^{27}$. It comprises 52 items, which are rated on a Likert scale ranging from 1 (not at all/poor) to 5 (extremely/ excellent), across the following ten dimensions:

Physical Wellbeing (5 items):This dimension refers to physical activity levels, energy and fitness (e.g., "Did you feel well and fit?").

Psychological Wellbeing: This dimension evaluates psychological wellbeing, including positive emotions and life satisfaction (e.g., "Did you feel satisfied with life?").

Mood (7 items): This scale includes seven items on negative experiences, depressive mood and feelings of distress (for example: "Did you feel sad?").

Self-perception (5 items): This dimension evaluates the subject's perception of self, physical appearance and satisfaction related to those aspects (e.g., "Were you concerned about your appearance?”).

Autonomy (5 items): This dimension includes five items that inquire about opportunities to utilise leisure time (e.g., "Were you able to choose what to do in your spare time?").

Relations with Parents \& Family Life (6 items):This dimension examines the respondent's relationship with his/her parents and the family atmosphere. It consists of six items (e.g., "Do your parents understand you? Are you able to talk to your parents whenever you want?").

Financial Resources (3 items):This dimension assesses the adolescent's perception of his/ her family's financial capacity (e.g., "Have you had enough money to do what your friends do?").

Social Support from Peers (6 items): This dimension reflects the nature of the subject's social relationships (e.g.") Have you been able to talk about everything with your friends?").

School Environment (6 items): This dimension assesses the individual's perception of his/ her aptitude for learning, concentration and feelings about school (for example "Have you done well in school?").

Social Acceptance (Bullying-rejection) (3 items): This dimension assesses feelings of rejection by peers. It includes three items (e.g., "Have you been bullied or threatened by other girls or boys?").

In the current study, the level of internal consistency measured by alpha of Cronbach was satisfactory for all of the subscales, as follows: Physical Wellbeing $\left(\alpha_{\mathrm{PT}}=.85, \alpha_{\mathrm{SP}}=.77\right)$, Psychological Wellbeing $\left(\alpha_{\mathrm{PT}}=.89, \alpha_{\mathrm{SP}}=.87\right)$, Moods and Emotions $\left(\alpha_{\mathrm{PT}}=.85, \alpha_{\mathrm{SP}}=.60\right)$, Self-perception $\left(\alpha_{\mathrm{PT}}=.60, \alpha_{\mathrm{SP}}=.65\right)$, Autonomy $\left(\alpha_{\mathrm{PT}}=.87, \alpha_{\mathrm{SP}}\right.$ $=.80)$, Relations with Parents $\&$ Family Life $\left(\alpha_{\mathrm{PT}}\right.$ $\left.=.87, \alpha_{\mathrm{SP}}=.88\right)$, Financial Resources $\left(\alpha_{\mathrm{PT}}=.91\right.$, $\left.\alpha_{\mathrm{SP}}=.90\right)$, Social Support \& Peers $\left(\alpha_{\mathrm{PT}}=.87, \alpha\right.$ $\left.{ }_{\mathrm{SP}}=.82\right)$, School Environment $\left(\alpha_{\mathrm{PT}}=.83, \alpha_{\mathrm{SP}}=\right.$ $.79)$, and Social Acceptance (Bullying-rejection) $\left(\alpha_{\mathrm{PT}}=.76, \alpha_{\mathrm{SP}}=.72\right)$.

Sociodemographic data: A questionnaire was developed ad hoc to collect the following data: adolescents' age and gender and mother and father's age, work status, labour qualification ( $1=$ low, 2 = medium and $3=$ high) and education level ( 1 = no education, 2 = elementary school, 
Table 1. Socio-demographic characteristics of the adolescents.

\begin{tabular}{|c|c|c|c|c|c|}
\hline & $\begin{array}{l}\text { Natives PT } \\
\text { M (SD) / \% }\end{array}$ & $\begin{array}{l}\text { Natives SP } \\
\text { M (SD) / \% }\end{array}$ & $\begin{array}{c}\text { Immigrants PT } \\
M(S D) / \%\end{array}$ & $\begin{array}{c}\text { Immigrants SP } \\
M(S D) / \%\end{array}$ & $\mathrm{~F} / \chi^{2}$ \\
\hline \multicolumn{6}{|l|}{ Gender } \\
\hline Female & $51.11 \%$ & $46.72 \%$ & $53.49 \%$ & $40.17 \%$ & 4.50 \\
\hline Male & $48.89 \%$ & $53.28 \%$ & $46.51 \%$ & $59.83 \%$ & \\
\hline Age & $14.88(1.45)$ & $14.25(1.46)$ & $14.20(1.69)$ & $14.64(1.68)$ & $5.34^{* * *}$ \\
\hline $\mathrm{N}^{\circ}$ of years in host country & - & - & $6.49(3.01)$ & $6.10(2.80)$ & 0.83 \\
\hline \multicolumn{6}{|l|}{ Origin } \\
\hline Africa & - & - & $14.63 \%$ & $12.62 \%$ & \\
\hline South America & - & - & $9.76 \%$ & $23.93 \%$ & \\
\hline Eastern Europe & - & - & $50.00 \%$ & $51.28 \%$ & \\
\hline Other & - & - & $25.61 \%$ & $11.97 \%$ & $10.59^{*}$ \\
\hline \multicolumn{6}{|l|}{ Family Structure } \\
\hline One-parent & $27.07 \%$ & $36.76 \%$ & $19.05 \%$ & $33.33 \%$ & \\
\hline Two-parent & $72.93 \%$ & $63.24 \%$ & $80.95 \%$ & $66.67 \%$ & $8.93^{*}$ \\
\hline \multicolumn{6}{|l|}{ Fathers' educational level } \\
\hline Uneducated & $17.29 \%$ & $27.21 \%$ & $3.57 \%$ & $24.56 \%$ & \\
\hline Elementary school & $46.62 \%$ & $29.41 \%$ & $33.33 \%$ & $34.21 \%$ & \\
\hline High school & $22.56 \%$ & $13.97 \%$ & $41.67 \%$ & $20.18 \%$ & \\
\hline University studies completed & $13.53 \%$ & $29.41 \%$ & $21.43 \%$ & $21.05 \%$ & $48.90^{* * *}$ \\
\hline \multicolumn{6}{|l|}{ Mothers' educational level } \\
\hline Uneducated & $12.12 \%$ & $24.82 \%$ & $4.71 \%$ & $29.31 \%$ & \\
\hline Elementary school & $34.09 \%$ & $27.74 \%$ & $28.24 \%$ & $26.72 \%$ & \\
\hline High school & $28.79 \%$ & $16.79 \%$ & $43.53 \%$ & $16.38 \%$ & \\
\hline University studies completed & $25.00 \%$ & $30.66 \%$ & $23.53 \%$ & $27.59 \%$ & $44.02^{* * *}$ \\
\hline Father does not work/unemployed & $16.54 \%$ & $25.55 \%$ & $14.81 \%$ & $23.93 \%$ & 5.74 \\
\hline Mother does not work/unemployed & $16.28 \%$ & $39.26 \%$ & $30.59 \%$ & $28.21 \%$ & $17.30^{* * *}$ \\
\hline \multicolumn{6}{|l|}{ Fathers' work qualification } \\
\hline Low & $48.80 \%$ & $37.61 \%$ & $46.84 \%$ & $63.33 \%$ & \\
\hline Medium & $34.40 \%$ & $37.61 \%$ & $37.97 \%$ & $32.22 \%$ & \\
\hline High & $16.80 \%$ & $24.77 \%$ & $15.19 \%$ & $4.44 \%$ & $20.29^{* *}$ \\
\hline \multicolumn{6}{|l|}{ Mothers' work qualification } \\
\hline Low & $46.15 \%$ & $52.75 \%$ & $60.76 \%$ & $79.07 \%$ & \\
\hline Medium & $27.69 \%$ & $30.77 \%$ & $27.85 \%$ & $13.95 \%$ & \\
\hline High & $26.15 \%$ & $16.48 \%$ & $1139 \%$ & $6.98 \%$ & $29.44^{* * *}$ \\
\hline School failures (in years) & $1.02(1.476)$ & $0.56(0.792)$ & $0.51(0.92)$ & $0.77(0.79)$ & $5.38^{* *}$ \\
\hline School absenteeism in last month & $1.63(1.76)$ & $1.58(1.59)$ & $1.57(1.47)$ & $1.76(1.81)$ & 0.30 \\
\hline Average of school grades & $3.31(1.26)$ & $2.74(1.05)$ & $2.71(1.13)$ & $2.61(1.16)$ & $9.82^{* * *}$ \\
\hline
\end{tabular}

${ }^{*} \mathrm{p}<.05 ;{ }^{* *} \mathrm{p}<.01 ;{ }^{* * *} \mathrm{p}<.001$

$3=$ high school and $4=$ university studies completed). Information about the adolescents' family structure, immigrant status, country of origin, and academic performance (number of failures, absenteeism in last month, and average grades on a scale from $1=$ poor to $5=$ excellent) was also gathered.

\section{Procedures}

The data were gathered in eight public schools in Algarve and thirteen public schools in
Huelva. The included schools were selected randomly among the schools in the region. School boards agreed to participate; and written consent from the Directorate General of Innovation and Curricular Development, Ministry of Education was obtained. Informed consent forms were requested and obtained from parents and adolescents. Participation was voluntary, and no compensation was offered. The instruments were completed in the classroom and administered by a trained interviewer. 


\section{Statistical analysis}

Statistical analyses were performed with IBMSPSS software v-20. Missing data at the item level were extrapolated using the missing value analysis of IBM-SPSS (EM algorithm). All the cases in which more than $10 \%$ of the questionnaire items were missing were removed from the analyses. Statistical assumptions for parametric tests were checked following Tabachnick and Fidell' ${ }^{28}$ recommendations, with satisfactory results.

Snedecor's $F$ test was used to compare the quantitative variables, and a Chi-square test was performed for the qualitative variables. MANOVAs were performed for the QOL scales. Kruskal-Wallis was used to compare groups when the assumptions of normality and homogeneity of variance were not validated.

\section{Results}

In Table 2, we present the descriptive statistics for the KIDSCREEN-52 subscales and the correlation coefficients obtained for the Portuguese and the Spanish participants. Most of the subscales were significantly correlated with each other. Correlations ranged between .14 and .74 for the Portuguese adolescents and .13 and .59 for the Spanish adolescents. Exceptionally, in both samples, the Social Acceptance subscale was not significantly correlated with the Physical wellbeing and School Environment subscales. The Portuguese adolescents scored higher than the Spanish adolescents on all the QOL subscales, with the exception of the Self-perception subscale.

We did not find any relationships between the QOL dimensions and academic variables, except between the number of school failures and Financial Resources $(r=.10, p=.04)$ and Social Support from Peers $(r=.10, p=.03)$. Additionally, when comparing younger adolescents (12-14 years) with older adolescents (15-17 years), we found no significant differences in the QOL dimensions. However, girls $(M=17.73, S D=4.21)$ presented lower scores than boys $(M=18.94, S D$ $=3.94)$ on the Physical Wellbeing subscale $(F=$ $10.32, p=.001, \eta^{2}=.02$ ).

With the aim of analysing differences in immigrant adolescents' QOL according to their country of origin, a Kruskal-Wallis test was performed. However, because no significant differences were found for this variable, and to enhance the statistical power of the following analysis, we did not cluster immigrant adolescents according to their country of origin. The MANOVA performed with the ten KIDSCREEN-52 subscales indicated that the four groups of adolescents differed in their QOL, $F(3,430)=3.50, p<.001$, with a median effect size, $\eta^{2}$ partial $=.08$, after controlling for gender and age (Table 3 ).

The subsequent ANOVAs showed that only Mood $\left(M_{\text {Nat } P T}=79.96, M_{\text {Nat } S P}=73.63, M_{\text {Inmi } P T}\right.$ $\left.=82.01, M_{I n m i} S P=70,99\right)$ and Social Acceptance

Table 2. Descriptive data and correlation coefficients between the subscales of the KIDSCREEN-52 $\left(\mathrm{n}_{\mathrm{pT}}=221, \mathrm{n}_{\mathrm{SP}}=254\right)$.

\begin{tabular}{|c|c|c|c|c|c|c|c|c|c|c|}
\hline & 1 & 2 & 3 & 4 & 5 & 6 & 7 & 8 & 9 & 10 \\
\hline 1. Physical well-being & - & $.493^{* * *}$ & $.437^{* * *}$ & $.349^{* * *}$ & $.440^{* * *}$ & $.343^{* * *}$ & $.302^{* * *}$ & $.363^{* * *}$ & $.366^{* * *}$ & .077 \\
\hline 2. Psychological Wellbeing & $.504^{* * *}$ & - & $.738^{* * *}$ & $.466^{* * *}$ & $.520^{* * *}$ & $.586^{* * *}$ & $.434^{* * *}$ & $.465^{* * *}$ & $.449^{* * *}$ & $.267^{* * *}$ \\
\hline 3. Moods and Emotions & $.293^{* * *}$ & $.586^{* * *}$ & - & $.552^{* * *}$ & $.511^{* * *}$ & $.480^{* * *}$ & $.417^{* * *}$ & $.416^{* * *}$ & $.373^{* * *}$ & $.311^{* * *}$ \\
\hline 4. Self-perception & $.384^{* * *}$ & $.401^{* * *}$ & $.428^{* * *}$ & - & $.351^{* * *}$ & $.406^{* * *}$ & $.226^{* *}$ & $.316^{* * *}$ & $.240^{* * *}$ & $.259^{* * *}$ \\
\hline 5. Autonomy & $.340^{* * *}$ & $.496^{* * *}$ & $.424^{* * *}$ & $.374^{* * *}$ & - & $.508^{* * *}$ & $.328^{* * *}$ & $.491^{* * *}$ & $.290^{* * *}$ & $.136^{*}$ \\
\hline 6. Relations with Parents \& Family Life & $.391^{* * *}$ & $.458^{* * *}$ & $.449^{* * *}$ & $.488^{* * *}$ & $.450^{* * *}$ & - & $.442^{* * *}$ & $.383^{*+*}$ & $.406^{* * *}$ & $.139^{*}$ \\
\hline 7. Financial Resources & $.363^{* * *}$ & $.365^{* * *}$ & $.328^{* * *}$ & $.305^{* * *}$ & $.316^{* * *}$ & $.383^{* * *}$ & - & $.490^{* * *}$ & $.239^{* * *}$ & $.201^{* *}$ \\
\hline 8. Social Support Peers & $.311^{* * *}$ & $.495^{* * *}$ & $.336^{* * *}$ & $.166^{* *}$ & $.519^{* * *}$ & $.314^{* * *}$ & $.326^{* * *}$ & - & $.278^{* * *}$ & $.315^{* * *}$ \\
\hline 9. School environment & $.193^{* *}$ & $.266^{* *}$ & $.202^{* *}$ & $.143^{*}$ & $.233^{* * *}$ & $.293^{* * *}$ & $.174^{* *}$ & $.215^{* *}$ & - & .049 \\
\hline 10. Social Acceptance & .094 & $.221^{* * *}$ & $.324^{* * *}$ & $.158^{*}$ & $.157^{*}$ & $.137^{*}$ & $.132^{*}$ & $.199^{* *}$ & .091 & - \\
\hline \multirow[t]{2}{*}{$\operatorname{MPT}\left(S D_{P T}\right)$} & 75.57 & 80.74 & 80.32 & 75.93 & 77.14 & 81.73 & 79.46 & 81.78 & 72.75 & 91.16 \\
\hline & (15.97) & (14.74) & (14.47) & (13.44) & (17.31) & (15.16) & (19.95) & $(14.88)$ & (14.32) & $(12.40)$ \\
\hline \multirow{2}{*}{$\operatorname{MSP}\left(S D_{S P}\right)$} & 71.57 & 78.08 & 71.60 & 76.10 & 77.04 & 79.54 & 74.18 & 78.96 & 69.66 & 85.82 \\
\hline & (16.68) & $(16.22)$ & (11.81) & (15.89) & (16.91) & (16.77) & (21.39) & (15.58) & $(15.68)$ & (16.19) \\
\hline
\end{tabular}

Note. Coefficients obtained for the Portuguese adolescents are above-right and for the Spanish are below-left " $\mathrm{p}<.05,{ }^{* *} \mathrm{p}<.01,{ }^{* * *} \mathrm{p}<.001$ 
Table 3. Comparison of the subscales Quality of life between the groups $\left(\mathrm{n}_{\text {Nat } P T}=131, \mathrm{n}_{\text {Nat } S P}=122, \mathrm{n}_{\text {Inmi } P T}\right.$ $\left.=84, \mathrm{n}_{\text {InmiSP }}=97\right)$.

\begin{tabular}{|c|c|c|}
\hline Control variables & F & $\begin{array}{c}\text { partial } \\
\eta^{2}\end{array}$ \\
\hline Adolescent's age & 0.73 & - \\
\hline Adolescents' gender & 1.49 & - \\
\hline Group & $3.50^{* * \star}$ & .08 \\
\hline Physical well-being & 1.41 & - \\
\hline Psychological Wellbeing & 1.03 & - \\
\hline Moods and Emotions & $17.57^{* * *}$ & - \\
\hline Self-perception & 1.41 & - \\
\hline Autonomy & 0.85 & - \\
\hline Relations with Parents \& Family Life & 1.03 & - \\
\hline Financial resources & 2.22 & - \\
\hline Social Support Peers & 0.91 & - \\
\hline School environment & 1.38 & - \\
\hline Social Acceptance & $4.87^{* *}$ & - \\
\hline
\end{tabular}

${ }^{*} \mathrm{p}<.05,{ }^{* *} \mathrm{p}<.01,{ }^{* * * *} \mathrm{p}<.001$

$\left(M_{N a t P T}=92.42, M_{\text {Nat } S P}=88.41, M_{\text {Inmi } P T}=90.87\right.$, $M_{\text {InmisP }}=86.53$ ) significantly differed between the four groups. Immigrant Portuguese adolescents scored higher on Mood, and native Portuguese adolescents scored higher on Social Acceptance.

\section{Discussion}

The main objective of our study was to investigate differences in QOL between immigrant and native adolescents. Our findings contradict the results of related research on immigrant families in affluent countries, as many studies have reported considerable differences in QOL between children from immigrant families and children from native families ${ }^{10}$.

However, it is consistent with other studies $^{29,30}$, which suggested that immigrant youth in thirteen different countries were as well adjusted as their non-immigrant peers. Our results may be also explained by the "immigrant health paradox" ${ }^{\prime 31}$. This is the finding that certain immigrant groups have similar or better health outcomes than native-born.

Several theories attempt to explain the immigrant paradox: The selectivity argument focuses on the immigrants themselves and argues that any health advantages that exist are due to immigrant self-selection; only the healthiest people immigrate. The sociocultural explanation focuses on the aspects of immigrant families and communities that may positively affect health or the health behaviours and beliefs immigrants may bring with them. According sociocultural explanation similar or better immigrant QOL could be explained by the positive effects of strong immigrant social networks ${ }^{32}$.

Furthermore, in the present study, the results concerning the QOL differences between the four groups (immigrants and natives from Spain and Portugal) indicated that Portuguese adolescents (both natives and immigrants) scored significantly higher only on the dimensions of Moods and Emotions and Social Acceptance, suggesting that Portuguese participants experienced fewer negative experiences and less depressive mood and distress compared to Spanish adolescents.

Portuguese youth also reported significantly lower feelings of rejection by peers. This result is discrepant with Hernando et al..$^{20}$ finding that adolescents living in Spain reported higher Social Acceptance (and therefore, lower feelings of rejection by peers and others) than their Portuguese counterparts. In terms of the remaining subscales, the perceptions of Autonomy, Relationships with Parents, Social Support and School Environment were quite similar across the four groups of adolescents. This finding indicates that in both countries, the living contexts for immigrant and native adolescents are fairly homogeneous, as previous studies have shown ${ }^{16,17}$.

These findings are encouraging because adolescents with closer relationships and better communication with their parents and friends have also reported a happier and more pleasurable life ${ }^{33-35}$. Additionally, relationships with friends, classmates, and teachers are negatively associated with substance use, and this association is mediated by certain factors, including psychological symptoms, wellbeing, and school satisfaction ${ }^{36}$.

The results of the correlations between the KIDSCREEN subscales in both samples indicated that all QOL dimensions were positively associated and that most dimensions were significantly related. Portuguese adolescents showed more positive perceptions of the majority of QOL dimensions, with the exception of Self-perception (the adolescent's perception about his/her body, self-esteem), which was somewhat higher in Spanish adolescents. These results are similar to those obtained by Gaspar and Matos ${ }^{9}$ in the Portuguese validation study of the KIDSCREEN-52 and are consistent with the results of several European countries ${ }^{3}$. 
Previous research that has been conducted on QOL with community samples has suggested that the perception of QOL is influenced by the adolescents' gender and age $e^{5,9}$ and by financial resources ${ }^{12}$. Furthermore, cross-culturally validated measures of QOL must be utilised to strengthen empirical findings.

A limitation of the current study is the fact that only one source of information was used. Although it has been stated that individuals' perception of their own wellbeing is a more reliable measure of their QOL than an objective health evaluation $^{5,12}$, parents', peers' and teacher's perceptions of the adolescents' QOL dimensions would have enriched this study. Additionally, the cross-sectional study design precludes the establishment of causal relations between the studied demographic variables and the factors identified in the KIDSCREEN-52.

One major asset of using the KIDSCREEN is that it allows cross-cultural comparisons; there-

\section{Collaborations}

C Nunes, A Hernando, I Lemos, L Ayala-Nunes, CR Oliva and CM Coronado contributed to the preparation of the manuscript.

\section{Acknowledgements}

This paper is financed by National Funds provided by FCT- Foundation for Science and Technology. fore, it may help to develop new prevention programs or to adapt existing programs to a particular target population ${ }^{4,6}$. Assessing QOL is an important means of monitoring the health status of the general population or of a specific population group, and this assessment should be conducted over time ${ }^{37}$. Additionally, such assessment allows us to detect subgroups of the population with lower QOL and evaluate the impact of interventions on public health in a given population $^{7}$. A longitudinal design would be a suitable method to distinguish causes and outcomes that affect adolescents' well-being throughout the process of acculturation ${ }^{19}$. Consequently, a future study should employ a longitudinal design to assess immigrant groups and other target groups with low QOL to evaluate the impact of public health interventions on these groups.

Overall, our results indicate that both native and immigrant adolescents seem to have satisfactory perceptions of their QOL.

\section{References}

1. Lin X-J, Lin IM, Fan SY. Methodological issues in measuring health-related quality of life. Tzu Chi Medical Journal 2013; 25(1):8-12.

2. Ravens-Sieberer U, Erhart M, Wille N, Wetzel R, Nickel J, Bullinger M. Generic health-related quality of life assessment in children and adolescents: Methodological considerations. Pharmacoeconomics 2006; 24(12):1199-1220.

3. Ravens-Sieberer U, Gosh A, Rajmil L, Erhart M, Bruil J, Duer W, Auquier P, Power M, Abel T, Czemy L, Mazur J, Czimbalmos A, Tountas Y, Hagquist C, Kilroe J, The European KIDSCREEN Group. KIDSCREEN-52 quality of life measure for children and adolescents. Expert Review of Pharmacoeconomics \& Outcomes Research 2005; 5(3):353-364.

4. Ravens-Sieberer U, Auquier P, Erhart M, Gosch A, Rajmil L, Bruil J, Power M, Duer W, Cloetta B, Czemy L, Mazur J, Czimbalmos A, Tountas Y, Hagquist C, Kilroe J, European KIDSCREEN Group. The KIDSCREEN-27 quality of life measure for children and adolescents: psychometric results from a cross-cultural survey in 13 European countries. Quality of Life Research 2007; 16(8):1347-1356

5. Michel G, Bisegger C, Fuhr DC, Abel T, The KIDSCREEN Group. Age and gender differences in health-related quality of life of children and adolescents in Europe: a multilevel analysis. Quality of Life Research 2009; 18(9):1147-1157.

6. Gaspar T, Matos MG, Ribeiro JLP, Leal I, Ferreira A. Health-related quality of life in children and adolescents and associated factors. Journal of Cognitive and Behavioral Psychotherapies 2009; 9(1):33-48. 
7. Matos MG, Gaspar T, Simões C. Health-related quality of life in Portuguese children and adolescents. Psicologia Reflexão e Crítica 2012; 25(2):230-237.

8. Aymerich M, Berra S, Guillaman I, Herdman M, Alonso J, Ravens-Sieberer U, Rajmil L. Desarrollo de la versión en español del KIDSCREEN. Un cuestionario de calidad de vida para la población infantil y adolescente. Gaceta Sanitaria 2005; 19(2):93-102.

9. Gaspar T, Matos MG. Qualidade de vida em crianças e adolescentes - versão portuguesa dos instrumentos KIDSCREEN-52. Cruz Quebrada: Aventura Social e Saúde; 2008.

10. Hernandez DJ, Macartney S, Blanchard VL. Children in immigrant families in eight affluent countries. Their family, national and international context. Florence: UNICEF Innocenti Research Centre; 2009.

11. Erhart M, Ravens-Sieberer U, Dickinson H, Colver A, the European SPARCLE and KIDSCREEN Groups. Rasch Measurement Properties of the KIDSCREEN Quality of Life Instrument in Children with Cerebral Palsy and Differential Item Functioning between Children with and without Cerebral Palsy. Value in Health 2009; 12(5):782-792.

12. Petersen-Ewert C, Erhart M, Ravens-Sieberer U. Assessing health-related quality of life in European children and adolescents. Neuroscience and Biobehavioral Reviews 2011; 35(8):1752-1756.

13. Vázquez ME, Muñoz MF, Fierro A, Alfaro M, Rodríguez L, Bustamante P. Estado de ánimo de los adolescentes y su relación con conductas de riesgo y otras variables. Revista de Pediatría de Atención Primaria 2013; 15(59):e75-e84.

14. Lemos I, Nunes C, Ayala-Nunes L. Quality of life and stressful life events in first and second generation immigrant adolescents. Journal of Spatial and Organizational Dynamics 2013; 1(3):209-221.

15. Santervás RL, González M, Suárez C. Comparación entre el nivel de salud de una muestra de adolescentes inmigrantes y nativos. Revista de Pediatría de Atención Primaria 2006; 8:595-604.

16. Neto F. Satisfaction with life among adolescents from immigrant families in Portugal. Journal of Youth and Adolescence 2001; 30(1):53-67.

17. Neto F. Psycho-social predictors of perceived discrimination among adolescents of immigrant background: A Portuguese Study. Journal of Ethnic and Migration Studies 2006; 32(1):89-109.

18. Berry JW. Acculturation: Living successfully in two cultures. International Journal of Intercultural Relations 2005; 29(6):697-712.

19. Bak-Klimek A, Karatzias T, Elliott L, Maclean R. The determinants of well-being among international economic immigrants: A systematic literature review and meta-analysis. Applied Research in Quality of Life 2015; 10(1):161-188.

20. Hernando A, Nunes C, Cruz MC, Lemos I, Valadas S. A comparative study on the health and wellbeing of adolescent immigrants in Spain and Portugal. Saúde e Sociedade 2013; 22(2):342-350.

21. Lima-Serrano M, Lemos I, Nunes C. Adolescent quality of life and health behaviors: A comparative study between adolescents from the south of Portugal and Spain. Revista Texto \& Contexto Enfermagem 2013; 22(4):893-900.
22. Amuedo-Dorantes C, Rica S. Labour market assimilation of recent immigrants in Spain. British Journal of Industrial Relations 2007; 45(2):257-284.

23. Marques MM, Rosa MJV, Martins JL. School and diversity in a weak state: The Portuguese case. Journal of Ethnic and Migration Studies 2007; 33(7):1145-1168.

24. Solé C. Immigration policies in Southern Europe. Journal of Ethnic and Migration Studies 2004; 30(6):12091221.

25. Guimarães S, Lemos I, Nunes C. Social skills and academic achievement in first and second generation adolescent immigrants in Portugal. Análisis y Modificación de Conducta 2012; 38(157-158):27-38.

26. The European KIDSCREEN Groupe. The KIDSCREEN questionaires. Lengerich: Pabst Science; 2006.

27. Pantzer K, Rajmil L, Tebé C, Codina F, Serra-Sutton V, Ferrer M, Ravens-Sieberer U, Simeoni MC, Alonso J. Health related quality of life in immigrants and native school aged adolescents in Spain. J Epidemiol Community Health 2006; 60(8):694-698.

28. Tabachnick BG, Fidell LS. Using multivariate statistics. $5^{\text {th }}$ ed. Boston: Pearson Education; 2007.

29. Neto F. Predictors of mental health among adolescents from immigrant families in Portugal. J Fam Psychol 2009; 23(3):375-385.

30. Berry JW, Phinney JS, Sam DL, Vedder P, editors. Immigrant youth in cultural transition: acculturation, identity, and adaptation across national contexts. Mawah: Lawrence Erlbaum; 2006.

31. Coll CGE, Marks AKE. The immigrant paradox in children and adolescents: Is becoming American a developmental risk? Washington: American Psychological Association; 2012.

32. Zambrano C. Health and young adulthood: Does immigrant generational status matter? Field Actions Science Reports 2010; 2 [Online]. [cited 2016 Feb 25]. Available from: http://factsreports.revues.org/507

33. Jiménez-Iglesias A, Moreno C, Ramos P, Rivera F. What family dimensions are important for health-related quality of life in adolescence? Journal of Youth Studies 2015; 18(1):53-67.

34. Raboteg-Saric Z, Sakic M. Relations of parenting styles and friendship quality to self-esteem, life satisfaction and happiness in adolescents. Applied Research in Quality of Life 2014; 9(3):749-765.

35. Vieira T, Alves N, Dias C, Fonseca A. Assimetrias regionais. Que diferenças nos estilos de vida e na satisfação com a vida dos adolescentes? Um estudo realizado em alunos do $3^{\circ}$ ciclo do Ensino Básico em Portugal. Cien Saude Colet 2015; 20(1):17-28.

36. Simões C, Matos MG, Batista-Foguet JM, SimonsMorton B. Substance use across adolescence: Do gender and age matter? Psicologia: Reflexão e Crítica 2014; 27(1):179-188.

37. Lippman LH, Moore KA, McIntosh H. Positive indicators of child well-being: A conceptual framework, measures, and methodological issues. Applied Research in Quality of Life 2011; 6(4):425-449.

Artigo apresentado em 31/03/2015

Aprovado em 11/09/2015

Versão final apresentada em 13/09/2015 